\title{
MORAL IDENTITY AND ECOLOGICAL BEHAVIOR IN ROMANIAN YOUNG ADULTS
}

\author{
Maria Claudia Ionescu ${ }^{1 *}$, Andreea Stan ${ }^{1}$ \\ ${ }^{1}$ University of Piteşti, Department of Psychology, Communication Sciences, and Social Work, \\ Târgu din Vale, No.1, 110040, Piteşti, Argeş County, Romania
}

\section{Current Trends in}

Natural Sciences

\begin{abstract}
Environmental professionals and activists draw attention on the negative effects that human actions have on the planet, actions that turn against us all, sometimes with dramatic consequences like human casualties. In recent years, there is a growing interest in Romania in the area of environmental protection. Many environmental organizations advocate responsible institutional and individual behavior toward nature. Despite the progress in the environmental legislation and the public debate on this subject, there are questions and doubts about law application and the level of public awareness concerning environmental protection. Research in the area of individual pro-environmental behavior is interested in identifying psychological variables (knowledge, perceptions, attitudes, values) and contextual factors (income, technological infrastructure, costs) associated with relevant individual behavior patterns aiming at limiting the harmful effect of human actions on the environment. One line of research studies the impact of moral aspects like values, norms, identity on pro-environmental behavior. Our study explores the relationship between moral identity and several dimensions of ecological behavior in a sample of 231 Romanian young adults. We identified significant correlations between moral identity and ecological behavior.
\end{abstract}

Keywords: ecological behavior, moral self-identity

\section{INTRODUCTION}

The impact of human behavior on the environment has been a topic of research and debate for several decades. The development of society, population growth and the encouragement of consumption have led to dramatic changes in the environment, and scientists are drawing attention on the effects of these changes on the quality of people's lives.

At economic level, the European Union supports a more ecological development program, which requires the more efficient use of resources. In this regard, Member States' governments, including Romania, have aligned their national environmental legislation with this goal. In addition, numerous environmental organizations advocate responsible institutional and individual behavior toward nature. However, all these initiatives and measures will not be enough, if at the individual level there will be no change in mentality that will result in a change in behaviour. It is necessary for each of us to be aware of the impact that our own behavior has on the environment and to take measures in this regard. 


\section{Ecological behaviour}

Ecological behavior is defined as behavior "that consciously seeks to minimize the negative impact of one's actions on the natural and built world (e.g., minimize resource and energy consumption, use of non-toxic substances, reduce waste production)" (Kollmuss and Agyeman, 2002). Ecological behaviors include: recycling, energy and water conservation, individual behaviors and choices that reduce the level of air pollution, environmental activism, environmental citizenship, support of public policies, etc. (Kaiser et al., 1999; Stern, 2000).

Stern (2000) emphasizes the distinction between intent-oriented definition (intention to change the environment in a positive way) and impact-oriented definition (behaviors that have a positive impact on the environment) of environmentally significant behavior.

In general, the empirical literature distinguishes among four types of proenvironmental behavior: environmental activism (active involvement in environmental organizations and demonstrations), nonactivist behaviors in the public sphere ("environmental citizenship" behaviors, such as petitioning on environmental issues and supporting policies that protect the environment), privatesphere environmentalism (e.g., green consumerism), and other environmentally significant behaviors including individual behavior in organizations (Turaga et. al., 2010).

\section{Ecological behavior, moral norm perspective and theory of planned behavior}

Van Liere and Dunlap (1978) use the norm-activation model (Schwartz, 1970) to explain the relationship between moral norms and environmentally related behavior, e.g. yard-burning behavior. This model proposes two conditions that influence behavior: individuals' awareness of the consequences that their actions have on others (AC) and their acceptance of responsibility for their own actions and consequences (AR). They found a significant relationship between AR and burning behavior, a weak association of AC with burning behavior (explained by the authors as being determined by situational factors) and a significant interaction between AR, AC and burning behavior (Van Liere and Dunlap, 1978).

Stern (2000) developed a value-belief-norm (VBN) theory of environmentalism in which he postulates a causal relationship between the following variables: personal values (altruism), a (ecological) view of the world, awareness of negative consequences and responsibility for eliminating these consequences, sense of obligation to take proenvironmental actions. Stern (2000) highlights four causes of environmentally relevant behavior: attitudinal factors (norms, beliefs, values), contextual factors (e.g., interpersonal influences, government regulations, and other social, economic, and political factors), personal capabilities (knowledge, skills, resources relevant to environmental protection), and habits. The author points out that in order to change behavior towards the environment it is necessary to combine intervention strategies and to identify the right combination to address the obstacles that prevent behavior change.

Bronfman et al. (2015) found out that VBN model explained particularly well the environmental behaviour subscale of power and water conservation. Nevertheless, the explanatory power of the model was weak for behaviours related to ecologically aware consumer behavior and ecological waste management.

There is a discrepancy between the attitude towards environmental protection and ecological behavior (Kaiser et al., 1999) and numerous studies are trying to explain the mechanisms underlying proenvironmental behaviors and identify strategies that can motivate individuals to act to protect the environment.

Other studies use the theory of planned behavior to explain the relationship between moral norms and ecological behavior. Theory of planned behavior links intentions to perform behaviors to 
attitudes toward the behavior (positive or negative evaluation of the behavior by the individual), subjective norms (how significant others view a specific behavior, do they approve or disapprove of the specific behavior) and perceived behavioral control (a person's perception of the ease or difficulty of performing the behavior) (Ajzen, 1991). Chan and Bishop (2013) replace attitudes with moral norms in the context of theory of planned behavior. In their study, moral norms were associated with a higher recycling intention.

Rezvani, Jansson and Bengtsson (2017) show that the effect of moral norms on the consumer adoption of pro-environmental products is mediated by the anticipated emotions, namely beliefs about an outcome's emotional consequences.

More and more studies include variables in the moral domain in explaining ecological behavior. Kaiser and colleagues (1999) propose a model in which, in addition to environmental knowledge and environmental values, the role of feelings of responsibility (the degree to which the individual feels responsible in relation to environmental pollution) in the prediction of ecological behavior intention is investigated, concluding that this model predicted more accurately ecological behavior intention.

In this paper we try to highlight the relationship between ecological behavior and the selfimportance of moral identity. Aquino and Reed (2002) define moral identity based on self-concept and social identity theories, namely "a self-conception organized around a set of moral traits" (p. 1424). Moral identity is seen as the mental representation of one's moral character held internally as a cognitive schema, and expressed to others externally through one's actions. The authors propose a measure of moral identity with two dimensions, which capture the distinction between private self and public self: Internalization ("the degree to which the moral traits are central to the selfconcept") and Symbolization ("the degree to which the traits are reflected in the respondent's actions in the world") (Aquino and Reed, 2002, p. 1427). Internalization is the private dimension of moral identity and being high in moral identity internalization does not indicate whether or not one is a moral person in a normative sense.

In contrast, the public dimension (symbolization) represents the degree to which people tend to express their moral identity externally through observable actions. A person who is high in moral identity symbolization is someone who tends to engage in visible activities that can communicate, to others, his or her commitment to certain moral goals and ideals. A person low in moral identity symbolization is less inclined to engage in public displays of moral aspects.

\section{MATERIALS AND METHODS}

The main research objective of this study is to investigate the relationship between moral identity and ecological behavior.

\section{Participants}

The sample consisted of 231 young adults: 36 (15.6\%) were males and 195 (84.4\%) were females. Participants' age varies from 19 to $35(\mathrm{M}=23.5, \mathrm{SD}=4.41) .101(43.7 \%)$ participants are high school graduates, $7(3 \%)$ are undergraduates, $93(40.3 \%)$ have a Bachelor degree, and $30(13 \%)$ have a Master's degree.

\section{Measures}

Participants completed two online measures: one assessing moral identity and another assessing ecological behavior.

The Self-importance of Moral Identity is a self-report 10-item inventory developed by Aquino and Reed, II (2002). It comprises a list of 9 moral character traits (e.g., caring, compassionate, fair). 
Participants were asked to picture a person with those traits while responding to 10 statements on a scale from 1 (completely disagree) to 5 (completely agree). The instrument measure two factors: Internalization (the degree to which the moral traits are central to the participant's self-concept) and Symbolization (the extent to which participants outwardly display a social identity based on the moral traits). Cronbach's alphas were .73 for Internalization and .82 for Symbolization in the validation study. For our sample, Cronbach's alphas were .80 for Internalization and .78 for Symbolization.

The General Ecological Behavior measure is a 38-item questionnaire developed by Kaiser (1998) and it assesses different types of ecological behavior: ecological garbage removal ("I put dead batteries in the garbage."), water and power conservation ("I prefer to shower rather than to take a bath."), ecologically aware consumer behaviour ("I use a chemical air freshener in my bathroom."), garbage inhibition ("Sometimes I buy beverages in cans."), volunteering in nature protection activities ("I am a member of an environmental organization."), ecological automobile use ("Usually I do not drive my automobile in the city."). The measure includes a non-environmental prosocial behavior scale. The responses consist in a Yes/No format. We have eliminated one item ("I usually buy milk in returnable bottles.") because it doesn't have an equivalent in Romanian reality and we added a third response alternative (I don't know) to the item "I use phosphate-free laundry detergent", assuming that many participant are not aware of this. This assumption was correct, 191 (82.7\%) participants choosing "I don't know", so we didn't include this item in the ecologically aware consumer behaviour scale score. 107 (46.3\%) participants responded to ecological automobile use scale, because they owned a car.

The internal consistency for the whole measure is .74 (Kaiser, 1998).

\section{RESULTS AND DISCUSSIONS}

\section{Results}

As we can observe in Table 1, there are small significant correlations between moral identity and ecological behavior dimensions.

Table 1. Correlations (r) between moral identity and ecological behavior dimensions

\begin{tabular}{|c|c|c|c|c|c|c|c|c|c|c|c|}
\hline Variable & 1 & 2 & 3 & 4 & 5 & 6 & 7 & 8 & 9 & 10 & 11 \\
\hline 1 & - & $.258^{* * *}$ & $.265^{* *}$ & .043 & .194 & .012 & .030 & .090 & .067 & $.273^{* *}$ & .072 \\
\hline 2 & & - & $.151^{*}$ & $.252^{* *}$ & -.113 & -.048 & .009 & $.282^{* *}$ & -.063 & .188 & .203 \\
\hline 3 & & & - & .113 & -.075 & -.031 & .065 & $.219^{* * *}$ & -.024 & $.450^{* *}$ & .113 \\
\hline 4 & & & & - & -.054 & .056 & $.227^{* *}$ & $.361^{* *}$ & -.048 & $.542^{* *}$ & .186 \\
\hline 5 & & & & & - & .089 & .062 & -.003 & .020 & .174 & .039 \\
\hline 6 & & & & & & - & $.165^{*}$ & .007 & .135 & $.526^{* *}$ & -.004 \\
\hline 7 & & & & & & & - & $.186^{* *}$ & .014 & $.550^{* *}$ & .061 \\
\hline 8 & & & & & & & & - & .016 & $.553^{* *}$ & $.186^{* *}$ \\
\hline 9 & & & & & & & & & - & $.350^{* *}$ & $-.280^{* *}$ \\
\hline 10 & & & & & & & & & & - & .074 \\
\hline 11 & & & & & & & & & & & - \\
\hline
\end{tabular}

*. Correlation is significant at the 0.05 level (2-tailed).

Note Variables: 1 Internalization, 2 Symbolization, 3 Prosocial behavior, 4 Ecological garbage removal, 5 Water and power conservation, 6 Ecologically aware consumer behavior, 7 Garbage inhibition, 8 Volunteering in nature protection activities, 9 Ecological automobile use, 10 General ecological behavior, 11 Age 


\section{Discussion}

As expected, there is a significant relationship, although small, between Internalization and Prosocial behaviour $(\mathrm{r}=.26, \mathrm{p}=.00)$. People who see themselves as having moral traits are more motivated to engage themselves in prosocial behavior. Self consistency has been used as an explanation for this relationship. A high internalized moral identity means that the network of morally relevant knowledge constructs is easily accessible for the person, both in terms of quantity and speed, within the working self-concept (Aquino et al., 2009). The need to maintain a consistency between moral self concept and observable actions motivates people to adopt prosocial behavior (Winterich et al., 2013). If people see themselves as having moral traits, they are more likely to adopt what they perceive to be moral behavior, and prosocial behavior is percieved as a type of behavior a moral person engages in.

There is also a significant and smaller correlation $(\mathrm{r}=.15, \mathrm{p}=.02)$ between Symbolization and Prosocial behavior, meaning that there is a weak association between the degree a person display to others his moral self and engaging in behaviours that benefit others. Winterich et al. (2013) have shown that Symbolization motivates recognized prosocial behavior, particularly among those with low moral identity internalization.

These results are consistent with Gotowiec and van Mastrigt's (2019) findings. The two authors showed that Internalization was a significant independent predictor of prosocial tendencies and that Symbolization also emerged as a significant independent predictor for these tendencies. Moreover, a multivariate regression model including internalization, symbolization and control variables (gender, social desirability) identified Symbolization as the only significant independent predictor of prosocial behaviours.

Internalization is significantly associated with General ecological behavior $(\mathrm{r}=.27, \mathrm{p}=.00)$. The more central moral traits are for an individual self-concept, the more likely is for him/her to engage in ecological behavior. This result is consistent with the line of research linking moral theories and ecological behavior, the literature emphasizing the role of moral norms and beliefs about environmental conditions and personal responsibility in predicting proenvironmental behavior (Turaga et al., 2010).

Symbolization is positively and significantly associated with Ecological garbage removal $(\mathrm{r}=.25, \mathrm{p}$ $=.00)$ and Volunteering in nature protection activities $(\mathrm{r}=.28, \mathrm{p}=.00)$. Perhaps these two sets of ecological behavior are the most "visible" to others. On the other hand, the public debate on environmental issues in Romania in the past years focused mainly on garbage recycling because we need to develop the necessary infrastructure in this area. Regarding environmental activism, there are initiatives by local NGOs and private companies (as part of corporate social responsibility) and they are usually well covered by the media, so people are aware of this kind of actions and that they have the opportunity to take part in them.

The positive correlation between Age and Volunteering in nature protection activities $(\mathrm{r}=-.18, \mathrm{p}=$ .00) reveals a greater interest for environmental volunteering as people get older. This may be explained by the fact that, when people reach a certain age and become financially more secure, they are more willing and able to take time off work to volunteer, although as people get older and assume more responsibilities, they have less time they can allocate to volunteering (Aquino and Reed, 2002).

The negative correlation between Age and Ecological automobile use $(\mathrm{r}=-.28, \mathrm{p}=.00)$ may be the effect of the adults' greater need for car use. Being an adult means more responsibilities (work, children rearing) and more time constraints. Using the personal car for transportation means more 


\section{Current Trends in Natural Sciences}

Vol. 9, Issue 17, pp. 301-306, 2020

https://doi.org/10.47068/ctns.2020.v9i17.038

Current Trends in Natural Sciences (on-line)

ISSN: 2284-953X

Current Trends in Natural Sciences (CD-Rom)

ISSN: 2284-9521

ISSN-L: 2284-9521

ISSN-L: 2284-9521

freedom of movement and a more comfortable way to get to different places, in contrast to public transportation means, which need improvement in Romania in terms of time efficiency.

Limitations of the study

The main limitation of the study is related to the small sample size, which is not representative for Romanian young adult population.

\section{CONCLUSIONS}

Our study has shown that there are positive associations between moral identity and different dimensions of ecological behavior. Although personal differences are associated with ecological behaviour, they are just one category of factors related to environmental protection behaviour. Future research could investigate external factors (available infrastructure, government regulations, costs, education on environmental protection) associated with individual ecological behaviour in Romanian population.

\section{REFERENCES}

Ajzen, I. (1991). The theory of planned behavior. Organizational Behavior and Human Decision Processes, 50(2), $179-211$.

Aquino, K., Reed, A. II. (2002). The self-importance of moral identity. Journal of Personality and Social Psychology 83(6), 1423-1440. https://doi.org/10.1037/0022-3514.83.6.1423.

Aquino, K., Freeman, D., Reed, A. I. I., Lim, V. K. G., Felps, W. (2009). Testing a social cognitive model of moral behavior: The interaction of situational factors and moral identity centrality. Journal of Personality and Social Psychology, 97, 123-141. doi:10.1037/a0015406.

Bronfman, N.C., Cisternas, P.C., López-Vázquez, E., de la Maza, C., Oyanedel, J.C. (2015). Understanding Attitudes and Pro-Environmental Behaviors in a Chilean Community. Sustainability, 7, 14133-14152. doi:10.3390/su71014133.

Chan, L., Bishop, B. (2013). A moral basis for recycling: Extending the theory of planned behavior. Journal of Environmental Psychology, 36, 96-102.

Gotowiec, S., van Mastrigt, S. (2019). Having versus doing: The roles of moral identity internalization and symbolization for prosocial behaviors. The Journal of Social Psychology, 159(1), 75-91. doi: 10.1080/00224545.2018.1454394.

Kaiser, F.G. (1998). A general measure of ecological behavior. Journal of Applied Social Psychology, 28(5), $395-422$.

Kaiser, F.G., Ranney, M., Hartig, T., Bowler, P. A. (1999). Ecological behavior, environmental attitude, and feelings of responsibility for the environment. European Psychologist, 4(2), 59-74.

Kollmuss, A., Agyeman, J. (2002). Mind the gap: why do people act environmentally and what are the barriers to proenvironmental behavior? Environmental Education Research, 8(3), 239-260.

Liere K. D., Dunlap, R. E. (2006). Moral norms and environmental behavior: An application of Schwartz's normactivation model to yard burning. Journal of Applied Social Psychology, 8(2), 174-188.

Rezvani, Z., Jansson, J., Bengtsson, M. (2017) Cause I'll feel good! An investigation into the effects of anticipated emotions and personal moral norms on consumer pro-environmental behavior. Journal of Promotion Management, 23(1), 163-183.

Stern, P. C. (2000). Toward a coherent theory of environmentally significant behavior. Journal of Social Issues, 56(3), 407-424.

Turaga, R.M.R., Howarth, R.B., Borsuk, M.E. (2010). Pro-environmental behavior. Rational choice meets moral motivation. Annals of the New York Academy of Sciences, 1185(1), 211-224. https://doi.org/10.1111/j.17496632.2009.05163.x.

Winterich, K. P., Aquino, K., Mittal, V., Swartz, R. (2013). When moral identity symbolization motivates prosocial behavior: The role of recognition and moral identity internalization. Journal of Applied Psychology, 98(5), 759770. https://doi.org/10.1037/a0033177. 